\title{
Improved resistance management for durable disease control: A case study of phoma stem canker of oilseed rape (Brassica napus)
}

\author{
J.N. Aubertot ${ }^{1}$, J.S. West ${ }^{2}$, L. Bousset-Vaslin ${ }^{3}$, M.U. Salam ${ }^{4}$, M.J. Barbetti ${ }^{5}$ and A.J. Diggle ${ }^{6}$
}

${ }^{1}$ UMR d'Agronomie INRA/INA P-G, BP 1, 78850, Thiverval-Grignon, France; ${ }^{2}$ Rothamsted Research, AL5 2JQ, Harpenden, UK; ${ }^{3}$ UMR BIO3P INRA/Agrocampus Rennes, Domaine de la Motte, BP 35327, 35653, Le Rheu Cedex, France; ${ }^{4}$ Department of Agriculture, Western Australia, Centre for Cropping Systems, P.O. Box 483, 6401, Northam, WA, Australia; ${ }^{5}$ School of Plant Biology, The University of Western Australia, 35 Stirling Highway, 6009, Crawley, WA, Australia; ${ }^{6}$ Department of Agriculture, Western Australia, Baron-Hay Court, 6151, South Perth, WA, Australia;

\begin{abstract}
Specific resistance loci in plants are generally very efficient in controlling development of pathogen populations. However, because of the strong selection pressure exerted, these resistances are often not durable. The probability of a resistance breakdown in a pathosystem depends on the evolutionary potential of the pathogen which is affected by: (i) the type of resistance (monogenic and/or polygenic), (ii) the type of reproduction of the pathogen (sexual and/or asexual), (iii) the capacity of the pathogen for dispersal, (iv) the resistance deployment strategy (pyramiding of specific resistances, mixture of cultivars, spatio-temporal alternation), (v) the size of the pathogen population, which is affected by control methods and environmental conditions. We propose the concept of Integrated Avirulence Management (IAM) to enhance the durability of specific resistances. IAM involves a strategy to limit the selection pressure exerted on pathogen populations and, at the same time, reduce the size of pathogen populations by combining cultural, physical, biological or chemical methods of control. Several breakdowns of resistance specific to Leptosphaeria maculans, the causal agent of phoma stem canker have occurred in Europe and in Australia. This review paper examines control methods to limit the size of L. maculans populations and discusses how this limitation of population size can enhance the durability of specific resistances. It proposes pathways for the development of a spatially explicit model to define IAM strategies. Simulation results are presented to demonstrate the potential uses of such a model for the oilseed rape/L. maculans pathosystem.
\end{abstract}

Keywords: durability, Integrated Pest Management, Leptosphaeria maculans, population genetics, resistance breakdown, specific resistance

\section{Introduction}

The durability of control methods to limit or eradicate populations of living organisms is an important, generic issue in human societies. In the domain of human health, the development of resistance to antibiotics has been well documented and studied in bacteria. In the field of crop protection, the phenomenon of adaptation of pest populations to a means of control has been widely studied for chemical control against weeds, fungi, and insects (de Waard, 1993), including development of resistance in insects against genetically modified (GM) crops (Laxminarayan and Simpson, 2002). Lastly, genetic control of fungal, bacterial and viral plant pathogens can also lack durability (McDonald and Linde, 2002; Parlevliet, 2002).

It is therefore important to develop methods to preserve the efficacy of available genetic or chemical means to control pathogen populations. For crop protection, models have been developed to enhance the durability of pest control methods. In addition to specific breeding strategies, such as pyramiding (McDonald and Linde, 2002), several approaches have been proposed to enhance the durability of resistance to plant pathogens. These generally consist of (i) changing the proportion of resistant cultivars in a given region using non-spatially explicit models (Kiyosawa, 1982; Shi-Mai, 1991; van den Bosch and Gilligan, 2003), (ii) using mixtures of cultivars (Wolfe, 1984; Mundt, 2002), or (iii) spatio-temporal deployment of different resistances (Kiyosawa, 1982; Holt and Chancellor, 1999). Similarly, for GM crops, various models have been proposed to help define strategies to limit the selection pressure exerted on the pest populations through (i) the adaptation of refuge size (Laxminarayan and Simpson, 2002; Linacre and Thompson, 2004), (ii) refuge size 
and spatial organisation (Caprio, 2001; Vacher et al., 2003), (iii) refuge size, spatial organisation and crop rotation (Peck et al., 1999; Onstad et al., 2001). Computerised simulations of the evolution of insect resistance to insecticides indicated that insecticide rate, refuge size and rotation of insecticides with different modes of action could enhance the durability of the efficacy of chemical control (Gazzoni, 1998). However, these models usually take into account only one control method. Nonetheless some models aimed at defining management strategies for a non-durable method of control do integrate additional control methods. For GM crops, Storer et al. (2003) and Cerda and Wright (2004) integrated refuge size, spatial organisation, crop rotation and pesticide use on the refuge in their models to help preserve the efficacy of GM crops. In addition, non-chemical controls (such as tillage, fallow periods and sowing rate) have been generally integrated into models to develop strategies for management of herbicide resistance (Cavan et al., 2000; Neve et al., 2003). Likewise, Integrated Resistance Management (IRM) programs have been successfully developed to prevent the adaptation to insecticides oftobacco whitefly (Bemisia tabaci) and other pests (Palumbo et al., 2001).

With regard to the durability of genetic resistances to pathogens, fewer integrated approaches have been conducted, no doubt because of the complexity of the pathosystems. One idea proposed is the integrated management of cultivar resistance group simultaneously with fungicide application (Crute, 1984; Wolfe, 1984). For example, different powdery mildew resistance sources could be used for spring and winter barley, while permitting only specific fungicides on each crop type to isolate pathogen populations on the two barley types and hence limit evolutionary potential. Wolfe (1984) extended the idea to alter crop cultivars grown each year (in a cultivar mixture rather than with different cultivars in different fields), simultaneously altering either the chemical used or the cultivar protected by it. Where different diversification groups are available, the groups in use may be rotated each season so that any one particular group is initially unprotected for one or two seasons, then protected by a fungicide, before being omitted from cultivation completely for at least one season.

Understanding the selection occurring in a local pathogen population is complex as it is influenced by sub-populations on wild host plants, spore release from old debris (of previous cultivars), and long-distance immigration of spores or seed-borne inoculum in addition to inoculum produced on the range of cultivars currently grown in a region. Due to local differences in the pathogen population, classification of cultivar resistance for advising growers each season is therefore usually based on trials done in several locations within a particular country or region. However, classification of 'field resistance' is a combination of different components: qualitative, race-specific resistance; quantitative polygenic resistance, disease escape and tolerance, which may each be affected by cultural and environmental factors. Various cropping practices can decrease disease severity or increase 'field resistance' and therefore reduce selection of a pathogen population virulent on the current cultivars. Integrated management of pathogens can increase the durability of the resistances used for their control (McDonald and Linde, 2002; Mundt et al., 2002; Parlevliet, 2002), but there is a general lack of knowledge on how to integrate several methods to enhance the durability of resistances. Therefore, it is important to develop tools to integrate methods to limit the selection pressure exerted on the populations by resistances and to limit the inoculum size of pathogen populations. We propose the expression "Integrated Avirulence Management" (IAM) to describe this concept.

IAM involves not only limiting the selection pressure exerted by specific resistances on pathogen populations using a gene deployment strategy, but also limiting the inoculum size of the pathogen populations using an appropriate combination of control methods. These methods can be cultural, physical, biological or chemical. The gene deployment strategy can comprise alternating genetic resistances in time and space, or pyramiding resistances into a single cultivar. The deployment strategy can be applied at plant level (pyramiding), at field level (cultivar mixtures, species mixtures, multi-lines and multi-blends), at the farm level (inter-field diversification), or at the regional level (inter-field diversification, Adugna, 2004). With regard to the deployment in time, resistance genes can be released sequentially (a new resistance is introduced as soon as resistance breakdown occurs), or different genetic resistances can be used in different seasons. The physical area to which the definition of IAM applies depends on the capacity of the pathogen for dispersal. Although this integrated management is proposed for specific resistances, it can be applied to quantitative resistances.

We illustrate the concept of IAM using phoma stem canker (Leptosphaeria maculans), one of the most serious diseases that affects oilseed rape worldwide (Fitt et al., 2006). The main control of this disease is 
genetic through specific and quantitative resistances (Delourme et al., 2006). McDonald and Linde (2002) proposed a model that predicts the risk of specific resistance breakdown for several pathosystems on a 4-11 scale, with higher values indicating greater risk of resistance breakdown. With this model, the Leptosphaeria maculans/oilseed rape pathosystem was scored as 7-8. This high level of risk of specific resistance breakdown results from the evolutionary potential of the pathogen that undergoes a combination of sexual and asexual reproduction and has a medium genotypic flow (West et al., 2001). The high score given by this model is consistent with observations of several specific resistance breakdowns that have occurred in Europe (Rouxel et al., 2003) and, more recently, Australia (Li et al., 2003a,b, 2004; Sprague et al., 2006). This review paper analyses the methods (cultural, physical, chemical, and biological) that can limit the size of Leptosphaeria maculans populations, then demonstrates how this limitation can enhance the durability of specific resistances in the considered pathosystem. Finally, it proposes pathways for the development of a spatially explicit model to define IAM strategies and provides preliminary simulation results.

\section{Cultural, physical, chemical and biological control of Leptosphaeria maculans}

Cropping practices affecting the severity of phoma stem canker include crop rotation, stubble management and tillage, sowing date, fungicide regime, plant density and fertiliser use. The first group (crop rotation, stubble management and tillage) concerns ways of reducing exposure of crops to inoculum. Similarly, sowing date can be changed to avoid exposure to air-borne spores completely or at least during the period when the crop is most vulnerable. Sowing date may also be changed to avoid excessively hot periods, which can stress plants and exacerbate the impact of the disease (West et al., 2001). Fungicide regime is included here as an agricultural practice that when used correctly can substantially reduce final disease severity, but which for some regions is not an economic option. Other factors such as plant density and soil nutrition affect the severity of disease in various ways through disease escape or increasing crop tolerance.

\section{Cultural and physical control}

Reducing exposure of the crop to inoculum by disposal of stubble and using crop rotation to maximise separation between recent debris and the current crop is an important strategy for disease control. Similarly, tillage regime has a large effect on inoculum availability through differences in the burial or destruction of debris bearing pathogen fruiting bodies. This not only influences dispersal gradients of air-borne ascospores but also prevents conidia being rain-splashed directly from stubble in close proximity to plants (Thu" rwa" chter et al., 1999). The most common primary inoculum is airborne ascospores, which are usually released after rain over several weeks, from pseudothecia formed on remains of infected plants. Tillage regimes tested in Canada by Turkington et al. (2000) confirm that burial helps the breakdown of debris but that the woody root and crown debris is more persistent than upper stem debris. After 3 years, residue levels were generally low following all tillage regimes tested (including zerotillage), indicating that a rotation with at least 4 year intervals is advisable to reduce phoma stem canker in that location. This contrasts to the situation in southeastern Australia where crop residues and ascospore loads decrease substantially after 18 months (Marcroft et al., 2003).

Typically, ascospore dispersal gradients follow a negative exponential (or a power function, or a Cauchy) distribution with most spores deposited within $500 \mathrm{~m}$ of the source, especially the first $100 \mathrm{~m}$, but with some risk to crops up to several kilometres away (West et al., 2001; Marcroft et al., 2004). However, dispersal gradients are modified substantially by wind speed and local topography. Although the small number of spores likely to travel considerable distances pose little risk of initiating severe disease in the current season, these spores could represent new races or pathotypes, which can then become established in a region. The dispersal and deposition of many air-borne particles, such as plant pathogen spores and plant spores or pollens, has been modelled to optimize separation distances. This approach can be applied to calculate the risk of nearby inoculum sources for infection of oilseed rape crops by ascospores of L. maculans. Further work is required to quantify the relative proportions of background air-borne spores that have travelled long distances and those produced locally. 
Currently, a separation of crops from stubble sources of only $500 \mathrm{~m}$ is recommended in Australia. This distance is short because current cultivars are generally more resistant than those grown in the 1970s, use of minimum tillage practices is widespread and the acreage of oilseed rape grown is increasing, making large separation distances from stubble sources difficult (Barbetti and Khangura, 1999). Due to the dispersal characteristics of ascospores, and the separation distances recommended, the size of crop areas may also act as a cultural method to reduce disease in combination with crop rotation. In the UK, there has been a tendency in recent years for several 'traditional farms' to be managed as one, often with the same crops being grown in adjacent fields, although cultivars with different maturities are used to lengthen the duration of the harvest and to diversify disease resistance genes. Further work is required to assess the impact of rotating relatively large crop areas compared to smaller areas. Although larger cultivated areas increase the size of sources of ascospores (from the previous season's crop debris), separation distances between the current and previous season's crops are also larger, causing dilution of spores in the atmosphere. This is generally likely to decrease disease incidence, but increase spatial heterogeneity in disease severity.

The timing of ascospore release makes sowing date crucial. Poisson and Pe're`s (1999) demonstrated that early leaves (i.e. the first two true leaves) are more readily infected than later leaves (leaves 4 or 6), although phoma leaf spots may take longer to appear on early leaves. Previous work has shown that infection of cotyledons or leaves early in the season produces severe phoma stem cankers before harvest (Hammond and Lewis, 1986; Poisson and Pe're`s, 1999; Aubertot et al., 2004a). In some areas, such as the dry Mediterranean climate of Western Australia, where the first rains of the season often synchronise the release of air-borne ascospores with seedling emergence, severe canker or even death results as the stem of seedlings up to the six leaf stage may be completely severed at the base (Barbetti and Khangura, 1999). Similar symptoms have been reported on spring rape in Canada (Kharbanda, 1993). In much of Western Europe, there is usually sufficient soil moisture to sow seeds in late summer to establish plants that have produced several leaves by the time L. maculans ascospores are first released, avoiding infection at the crop's most vulnerable stage (LePage and Penaud, 1995). This may explain why seedling death due to hypocotyl infection is rare in Europe (Paul and Rawlinson, 1992). However, if late harvesting of crops or poor weather delays sowing or emergence, crops may still be relatively young when ascospores initiate infections. Zhou et al. (1999) and Sun et al. (2001) showed that in the UK, early appearance of crown canker symptoms was associated with greatest yield loss, with a thermal time from onset of leaf spotting to canker appearance that differed between cultivars. However, an exception due to disease escape often occurs in some central and eastern European countries such as Poland, where autumn leaf infections occur but severe crown cankers are very rare. This is thought to be because infections caused by early (autumn) spore releases [in Poland] often do not reach the stem because early frosts cause leaves to drop off prematurely. The cold winter weather largely prevents further spore release, leading to a second peak of spore release in the spring, which leads to infection of upper stems.

Other agricultural practices affecting disease severity include plant (sowing) density and fertilizer regime. A dense stand tends to produce plants with longer petioles and causes shaded leaves, low in the canopy, to be shed sooner than in stands of low plant density, in which plants receive better illumination. Hence higher plant densities promote disease escape or delay the pathogen reaching the stem. Conversely dense stands and excessive fertilizer treatment can produce relatively tall, thin stemmed plants, which ultimately may be more prone to lodging. Further research is required to understand effects of plant density on phoma stem canker severity and yield. Spring nitrogen fertilization has no effect on phoma stem canker severity (Sochting and Verreet, 2004), but high autumn nitrogen availability (i.e. more than $250 \mathrm{~kg} \mathrm{ha}-1$ ) increases phoma stem canker severity (Aubertot et al., 2004a).

\section{Chemical and biological control}

Chemical control of phoma stem canker includes seed treatments, coated fertiliser granules or fungicide sprays to foliage or stubble, depending on the disease epidemiology and crop economics (West et al., 2001). Foliar fungicide applications are used only where potential yields are high, such as Western Europe, rather than in areas where shorter day-lengths and heat-induced early senescence cause lower yields. Generally, foliar fungicide applications have an impact on final canker severity only if applied at the optimal time (West et al., 2002). Penaud et al. (1999) reported a system developed in France to improve fungicide use based on infection 
risk and agronomic factors. Imminent infection (7 rain-days after sowing, maturation of pseudothecia or first detection of $>20$ ascospores per day) triggers the decision to apply a fungicide if agronomic factors (cultivar susceptibility, soil type, growth stage and plant vigour) favour disease. The optimal timing for foliar fungicide applications in England is soon after the onset of significant leaf spotting (i.e. $>10-20 \%$ plants affected) as this prevents new leaf infections, whilst preventing stem infection from existing leaf lesions due to fungistatic and fungicidal effects (West et al., 2002). However, this approach relies on regular disease assessment in crops, particularly if plants are small, as the incidence of leaf spotting can increase rapidly and the fungus can reach the stem of small plants relatively quickly. To reduce the need for regular assessment of crops, the onset of phoma leaf spot and therefore, fungicide timing, can now be predicted. The model developed by Salam et al. (2003) predicts the onset of pseudothecial maturity in Australia when 43 suitable days (as defined by temperature and rainfall parameters) have occurred since harvest. Following the onset of maturity, ascospore showers are predicted when daily rainfall exceeds a threshold. This model is very accurate under Western Australian conditions and is used as a decision support tool for advising sowing date. Further models suited to other regions are under development to predict ascospore release or the first appearance of phoma leaf spot from temperature and wetness or rainfall data.

Chemical treatment of stubble to inhibit sporulation or even kill the pathogen has been described previously (Humpherson-Jones and Burchill, 1982; Rawlinson et al., 1984; Petrie, 1995) and a new group of chemicals has now been tested (Wherrett et al., 2003). When dry crop debris were temporarily immersed in fluquinconazole, flutriafol (technical grade) or glyphosate-ammonium, pseudothecial maturation and subsequent ascospore discharge were delayed. A practical solution such as spraying stubble and weeds after harvest could therefore help the crop to evade infection at the most vulnerable growth stages.

Several microbiological control agents that might control phoma stem canker development have been tested. The bacterium Erwinia herbicola was highly antagonistic to L. maculans in vitro through antifungal substance secretion (Chakraborty et al., 1994). Another bacterium, Paenibacillus polymyxa strain PKB1, produces antifungal peptides (Beatty and Jensen, 2002). This bacterium significantly reduced germination and germ-tube length of L. maculans conidia in vitro, decreased incidence and severity of leaf lesions in growth chamber tests, and decreased survival of the fungus on infected oilseed rape stubble in field experiments (Kharbanda et al., 1999). Cyathus striatus, a bird's nest fungus, also has antagonistic effects against L. maculans via two mechanisms. It possesses a greater ability for primary resource capture (greater production of cellulase and lignase than L. maculans) and produces an antibiotic complex named cyathin (Maksymiak and Hall, 2000). Furthermore, a biopreparation based on spores from the fungus Trichoderma harzianum reduced the severity of L. maculans leaf lesions in field experiments (Hysek et al., 2002). However, none of these biological control agents are currently used by farmers to control L. maculans and the potential for their wide-scale deployment is unknown.

\section{Size of pathogen populations and durability of resistances}

Five evolutionary forces, described below, influence pathogen population evolution (McDonald and Linde, 2002) but differ in their relative importance in the oilseed rape/ L. maculans pathosystem in relation to durability of resistances.

\section{Evolutionary forces that act on pathogen populations}

Mutation is the ultimate source of genetic variation, leading to the appearance of new alleles in the population. In a gene-for-gene relationship between pathogen and plant host, mutation from avirulence to virulence is required in the pathogen to generate individuals able to overcome the corresponding resistance gene in the plant. Mutation rates are generally low, and vary between loci and pathogens (McDonald and Linde, 2002). However, for a given mutation rate, the larger the pathogen population, the higher the probability that virulent mutants will appear. Furthermore, as increasing numbers of virulent mutants are generated, the diversity of genetic backgrounds in which further mutations to virulence occur increases, thus increasing the probability that well adapted mutants will arise. 
Genetic drift may lead to a loss of alleles over time in small populations, or populations going through regular reductions in size. However, this loss of alleles will only occur in the absence of selection. Alleles experiencing selection pressure will persist, whatever the size of the population. Drift may lead to a random loss of inessential virulence alleles on a susceptible plant cultivar but on a resistant cultivar these alleles will not be lost by drift because they are required for pathogen infection.

Migration allows the exchange of alleles between different populations. From a source of propagules, the dispersal gradient is defined as the expected number of propagules reaching a given distance. The number of propagules usually decreases with increasing distance, and, depending on the nature of propagules and the dispersive agent (wind, rain, vectors, human activities), the pathogen dispersal gradient may vary in steepness. However, for a given gradient, increasing the size of the source population will increase both the number of propagules dispersed to a given distance, and the probability that some propagules will travel further.

Recombination in plant pathogens is generally considered to promote adaptation of populations by promoting the association of several necessary alleles. If a combination of several virulence alleles is necessary to infect a cultivar, a strictly asexual pathogen will need to accumulate these virulences by successive mutations in the same genotype, whereas sexual reproduction will enable the combination of two or more alleles that appeared independently in different genotypes. In large populations, increased numbers of mutants and reduced genetic drift will promote higher diversity, and therefore increase probability for combinations of virulences to occur. However, to undergo sexual reproduction, opposite mating types of plant pathogens must meet and cross on the same plant or its residues. Therefore, recombination can occur only between those alleles that are not necessary to infect the cultivar. In other cases, either the two genotypes do not meet because they cannot infect the same plant, or they meet but both already possess the same alleles so recombination does not confer any advantage. A disadvantage of sexual reproduction is the need to find the opposite mating type in order to produce progeny. As stated above, mating types of obligatory heterothallic pathogens must meet on the same plant to cross, and are restricted to passive dispersal (they cannot look for each other as insects do). In large populations, finding the opposite mating type will not be a problem because incidence of the disease is high and most plants are infected by several genotypes. However, to overcome resistance genes, when populations are very small on the resistant cultivar, finding the opposite mating type may become a limiting factor. This problem may be reduced in L. maculans as saprophytic colonization of debris by pathotypes that would be avirulent on the living plant could enhance the prospect of crosses with virulent pathotypes.

Selection for virulence, selection against virulence (fitness cost) and selection for aggressiveness are critical evolutionary forces involved in the process of resistance breakdown. In the gene-for-gene relationship, major resistance genes oblige the pathogen to possess the corresponding virulence allele. Therefore, as soon as a resistant cultivar is grown in a region, virulent genotypes have an advantage over avirulent ones, in the proportion of the respective acreages. Strategies that moderate the selection pressure by diversification of genes in space or time have been reviewed previously (Finckh et al., 2000; McDonald and Linde, 2002; Mundt, 2002). In general, the larger the acreage of a resistant cultivar, the greater the advantage of virulent genotypes - regardless of the size of pathogen populations. The effect of increasing the total pathogen population in the region (i.e. on susceptible cultivars) will be to generate a larger number of virulent genotypes through mutation, more combinations of alleles through recombination and more migration of these compatible genotypes onto the resistant cultivars, all of which will increase the size of populations on the resistant cultivars.

Selection against virulence, or a fitness cost for the virulent individuals over avirulent ones, has often been introduced into models of pathogen population evolution (Kiyosawa, 1982; Leonard, 1997; Damgaard, 1999). Without a fitness penalty, the only stable state that a model could reach is ascendancy of multi-virulent individuals, which does not correspond to what is observed in the field. The strength of this selection against virulence is still a matter of debate because of difficulty in measuring it. If one assumes that all single base pair mutations are similarly likely, then the equilibrium frequency of an allele is a simple function of its historical relative fitness. As mutations are rare, small differences in fitness should cause large differences in frequency, so often fitness costs for initially rare virulence alleles would be immeasurably small. Mutations that confer virulence against one type of resistance could lead to avirulence against another type of resistance, but may be equally fit in the absence of either. This process seems to vary among pathogens and loci and 
probably only applies when avirulent and virulent genotypes are in competition (i.e. on the susceptible cultivar). Furthermore, in the case of insecticide resistance in mosquitoes, where the initial fitness cost is very high, fitness is an adaptive trait and replacement by alleles with lower fitness cost occurs over time (Chevillon et al., 1999). In large pathogen populations, if the resource is limiting, competition between individuals is expected to be more severe, but on the other hand the diversity of genotypes in which mutation to virulence occurs is higher, thus increasing the probability of lower fitness costs or compensatory mutations. Selection pressure imposed by quantitative resistance is less documented than is the case for major gene resistance (gene-for-gene relationships). In the case of quantitative resistance, infection by the pathogen is not an all or nothing response, therefore the selection pressure imposed on the pathogen population is lower and as a consequence more difficult to study. Large populations of a pathogen increase the probability of selecting genotypes with increased virulence.

Durability of resistance, evolutionary forces and population size in the oilseed rape/L. maculans pathosystem

What is a durable use of resistance genes, and which forces act for and against adaptation of pathogen populations? In some cases, durability of resistance occurs at the level of the gene, and the pathogen is not able to become virulent. One famous case is the barley mlo gene for resistance against Blumeria graminis for which laboratory selection of virulent mutants was unsuccessful and no virulent isolates could be recovered from crops despite about 30 years of use in spring barley (Schwarzbach, 1998). In this case, three independent mutations are necessary for the fungus to become virulent and the only two virulent isolates available suffer a fitness cost (Lyngkjaer et al., 2000). Of course, breeders hope to find such genes but for L. maculans such combinations of virulence genes have not been found. Furthermore, virulent L. maculans isolates were present even before the introduction of the corresponding genes in the cultivars. This has been the case not only for genes originating in B. napus, but also in France for genes transferred into B. napus from the mustards B. juncea (Brun et al., 2000) and B. nigra (Brun et al., 2001) or in Australia for a gene introduced from B. rapa subsp. sylvestris ( $\mathrm{Li}$ et al., 2003b, 2005). In these cases, reducing the size of the population at the local level may reduce the occurrence of new mutants and virulence alleles may be lost through genetic drift. However, as virulent isolates are detected in populations in the complete absence of selection pressure, it appears unlikely that their fitness cost would be sufficient to hamper their build-up as soon as resistant plants were present.

In some cases individual plants may have durable resistance through combination or pyramiding of stable resistance genes. The underlying assumption of pyramiding is that it is more difficult for a pathogen to acquire several independent mutations than a single one. However, any separate use of the individual resistance genes elsewhere will reduce the efficacy of pyramiding (Kiyosawa, 1982). In the case of L. maculans, if virulent mutants are already present at low frequencies in the population, they would need to acquire only one allele to become virulent against two resistance genes. Isolates with multiple virulences may also be already present in the population, at a frequency below the detection threshold but would be exposed to a very strong selection pressure. Furthermore, once multi-virulent isolates are present in the population, corresponding resistance genes cannot be used either alone or in combination.

A final approach to enhance the durability of resistances occurs on a regional scale through strategic use of non-durable genes in a manner that prevents adaptation of the pathogen population, despite its ability to overcome individual genes or gene combinations. In this case what happens in each field (population of the fungus) should be distinguished from what happens at the level of a network of fields or a small region. At a regional scale, the group of fields from which the inoculum

is produced at the end of one growing season is mixed to form a metapopulation of the fungus and spread over all of the crops emerging in the next growing season. On this scale, maintaining low, stable frequencies of virulent alleles will enhance durability of resistance genes. The susceptible cultivars (on which virulence alleles are neutral) act as a source of virulent mutants, and resistant cultivars (on which virulence alleles will multiply) act as a sink. As long as the resistant cultivars remain only a sink, the composition of the metapopulation will not change over time. When the resistant cultivars contribute progeny to the next generation, no combination of the processes of mutation, drift, migration, recombination or fitness cost will 
be sufficient to counterbalance the selective advantage of virulent individuals growing on the whole acreage in contrast to avirulent individuals that do not.

\section{Durability in a metapopulation and cultural practices}

Until now, strategies aimed at increasing durability of resistance have generally sought to reduce selection pressure by diversification of resistance genes in space and/or time. However, the expected outcome from such strategies is a dilution that slows the process, but does not result in a stable equilibrium, unless a huge fitness cost is assumed. Much less attention has been paid to other possibilities, in the context of the metapopulation, that focus on preventing resistant cultivars from becoming a source of inoculum. To be a source from a resistant cultivar, L. maculans has to survive saprophytically and produce inoculum, which has to be dispersed onto oilseed rape fields in following seasons. All three processes could be hampered in the following ways:

1. Survival of the pathogen is altered by various stubble management practices described previously and fungicide sprays.

2. Inoculum is produced on oilseed rape residues as either ascospores arising from sexual recombination, or conidia from asexual multiplication. As a heterothallic obligatory pathogen, L. maculans can produce ascospores only if mycelia of opposite mating types meet on the same plant. Adapting the crop management of oilseed rape (sowing date and rate, nitrogen availability, fungicide application) can reduce the susceptibility and exposure of the crop to inoculum and therefore reduce the subsequent inoculum production.

3. Dispersal of inoculum from the resistant cultivar to the following year's crops depends on the spore type, the amount of inoculum and the locations of fields in successive years. Ascospores move between distant fields, whereas conidia at most will only reach adjacent fields. Therefore, unless the oilseed rape is grown in the same field each year, or sown adjacent to unburied residues from the previous season, the transmission of offspring from one generation to the next through conidia is likely to be very low. Spatio-temporal distribution of cultivars in a given region will therefore strongly affect the incidence and severity of leaf spot infections.

Thus cultural practices will play a major role in durability of resistances, if used on both resistant and susceptible cultivars so as to prevent resistant cultivars from acting as an inoculum source. On resistant cultivars, the amount of inoculum has to be reduced, and the success of dispersal constrained. The amount of inoculum produced may be lowered actively by soil tillage (Turkington et al., 2000), burning (Marcroft et al., 2003) or use of pesticides (Humpherson-Jones and Burchill, 1982; Rawlinson et al., 1984; Petrie, 1995; Wherrett et al., 2003, 2004). The success of dispersal can be constrained by making sure conidia do not survive from one season to the next (no consecutive rotation, no new crop adjacent to field residues of resistant cultivars). Concerning ascospores, the key point is to reduce the size of the population on resistant cultivars, which will both lower the distance at which migration will be significant and reduce inoculum produced if the size of the population is low enough so that individuals do not find an opposite mating type for sexual reproduction. Decreasing population size on the resistant cultivars also depends on the reduction of population size on susceptible cultivars. Smaller population sizes on susceptible cultivars are expected to reduce the number of virulent mutants, to lower the probability that such a mutation occurs in a background with low fitness costs, to enhance the loss of virulence alleles through genetic drift, and to lower allelic diversity so that fewer allelic combinations are generated by drift. Thus, smaller population sizes on susceptible cultivars reduce the probability that virulent mutants reach fields sown with otherwise resistant cultivars where they would not be prevented from obtaining an automatic selective advantage.

\section{Modelling for Leptosphaeria maculans Integrated Avirulence Management}

To apply IAM strategies, modelling is an essential tool to handle the complexity of a pluri-annual system, driven by environmental variables along with technical decisions taken by a group of stakeholders at a regional scale. In this section, pathways are presented for the development of a model aimed at defining IAM strategies. 
This model describes the effects of cultural practices of several farmers in a given region on the evolution of the genetic structure of the pathogen populations. To do so, cultural practices that greatly affect the pathosystem will be taken into account; changes over time in the regional spatial distribution of oilseed cultivars (with possibly different specific and quantitative resistances), stubble management (tillage, export, or burning), application of chemicals to leaves or stubble, sowing date and sowing rate, and nitrogen fertiliser inputs throughout the cropping systems (Figure 1). The distribution of infected stubble is predicted from the changes over time in regional spatial distribution of oilseed rape cultivars and stubble management. Application of chemicals to stubble may reduce and delay the production of primary inoculum. Temperature and rainfall affect the timing of pseudothecial maturity; the mature ascospores are released during a rainfall event and wind speed and direction indicate where the ascospores will be dispersed. The deposition of ascospores on oilseed rape crops also depends on crop density (affected by nitrogen availability at sowing), as long as the soil surface is not completely covered by the crop. The severity of stem canker depends on cultivar resistance, the use of foliar fungicides, sowing date and sowing rate, nitrogen availability at sowing and weather variables. Available models, such as SimCanker (Aubertot et al., 2004b), can be used to represent this particular stage in the epidemiology of phoma stem canker. The genetic structure of L. maculans populations is then simulated for each field in the region studied.

Figure 1. Flow chart of a spatially explicit model aimed to define Integrated Avirulence Management strategies for phoma stem canker of oilseed rape over several seasons.

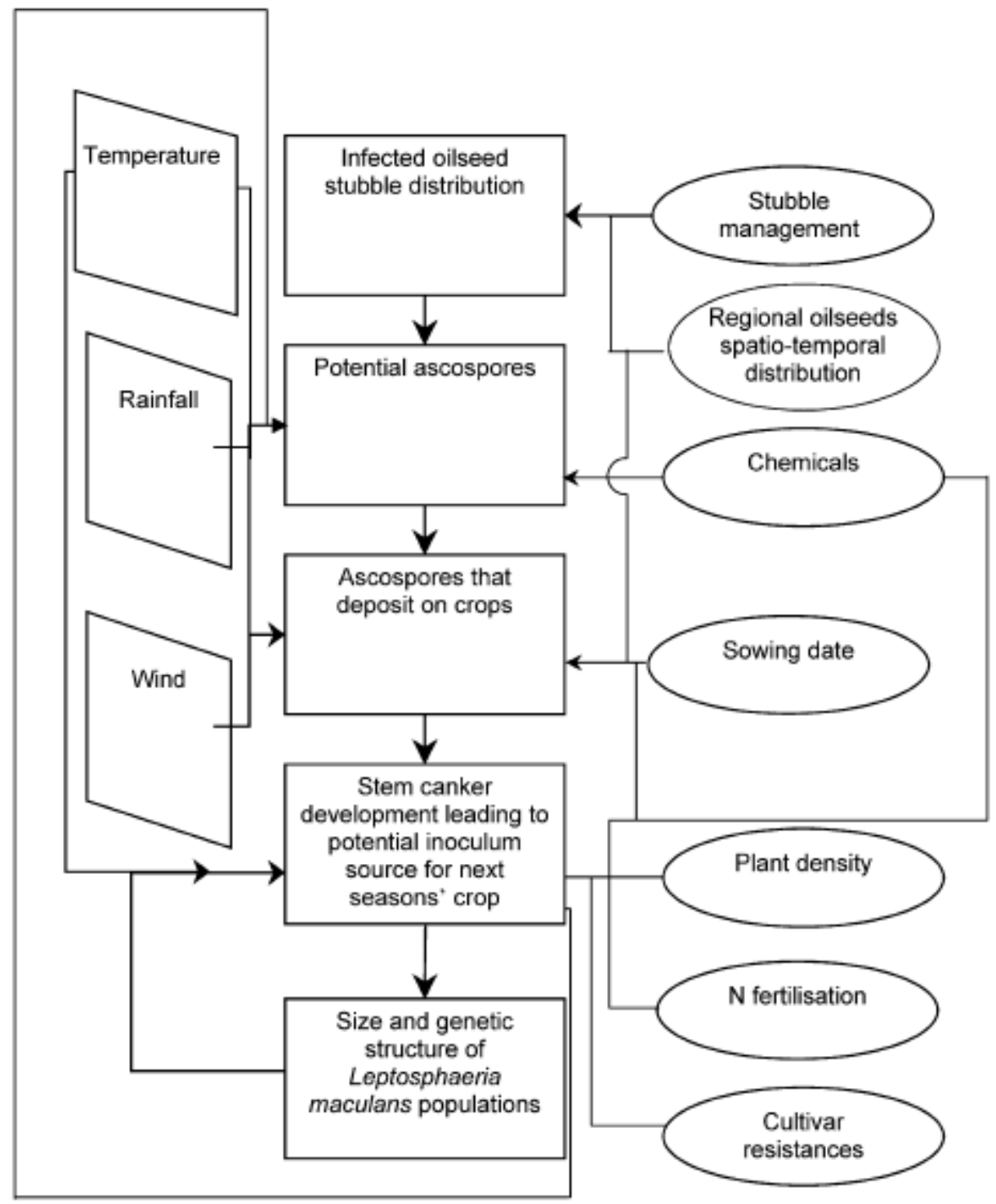


Preliminary simulations illustrate how such a tool could help to define integrated strategies to enhance the durability of specific resistance genes. Simulations are limited to the spread of ascospores for one season (only the 3 upper boxes are used in these simulations). The numerical model used to compute these simulations is a combination of three validated models: a model representing the effects of tillage operations on the vertical distribution of oilseed rape stubble (Schneider, 2005);

Sporacle (Salam et al., 2003); and Anthracnose Tracer (Diggle et al., 2002).

We modelled a part of Scaddan district of Western Australia (33.44_S and 121.72_E), a 17.2_17.5 km area, to indicate the pattern and intensity of ascospore dispersal. Figure 2 shows the simulated dispersal of ascospores for a period of 30 days after emergence in the current season from field 67, where an affected crop was grown the previous season. Local weather data for 1999 were used to run this simulation on an hourly basis, assuming a crop emergence date of $10^{\text {th }}$ May. The functions (relationship between weather variables and ascospore maturity and seasonal pattern of ascospore release) and related parameters used have been described (Salam et al., 2003). The ascospore dispersal function has two components, the angle and distance of dispersal, as characterised by the wind attributes. The wind induced dispersal angle is chosen from a normal distribution defined by the average wind direction, as measured by a weather station at $10 \mathrm{~s}$ intervals. The distance component is a random value chosen from a half-Cauchy distribution with a median dispersal parameter multiplied by the average wind speed $(\mathrm{m} \mathrm{s}) 1)$. This parameter is the median of the distribution distance (m) that spores may travel. Details of the dispersal function have been given by Diggle et al. (2002). The dispersal parameter of Salam et al. (2001) was used to describe dispersal of L. maculans ascospores in Western Australia.

Figure 2. Relative cumulated number of Leptosphaeria maculans ascospores $/ \mathrm{m}^{2}$ dispersed during 30 days after emergence on a $17.2 \times 17.5 \mathrm{~km}$ area of Scaddan district, Western Australia, from a source with $1.7 \times 10^{\circ}$ ascospores $/ \mathrm{m}^{2}$ ( $50 \times 50 \mathrm{~m}$ grid). The shading represents the proportion of ascospores dispersed from sources during 30 days after emergence $(\square 0 \%, \square 0-1 \%$, $\square 1-3 \%, \square 3-$ $8 \%$, $>8 \%$ ). The numbers correspond to each field represented on the map. The black line around field 67 illustrates the significance of the $500 \mathrm{~m}$ separation distance from the previous season's crop, suggested in Western Australia.

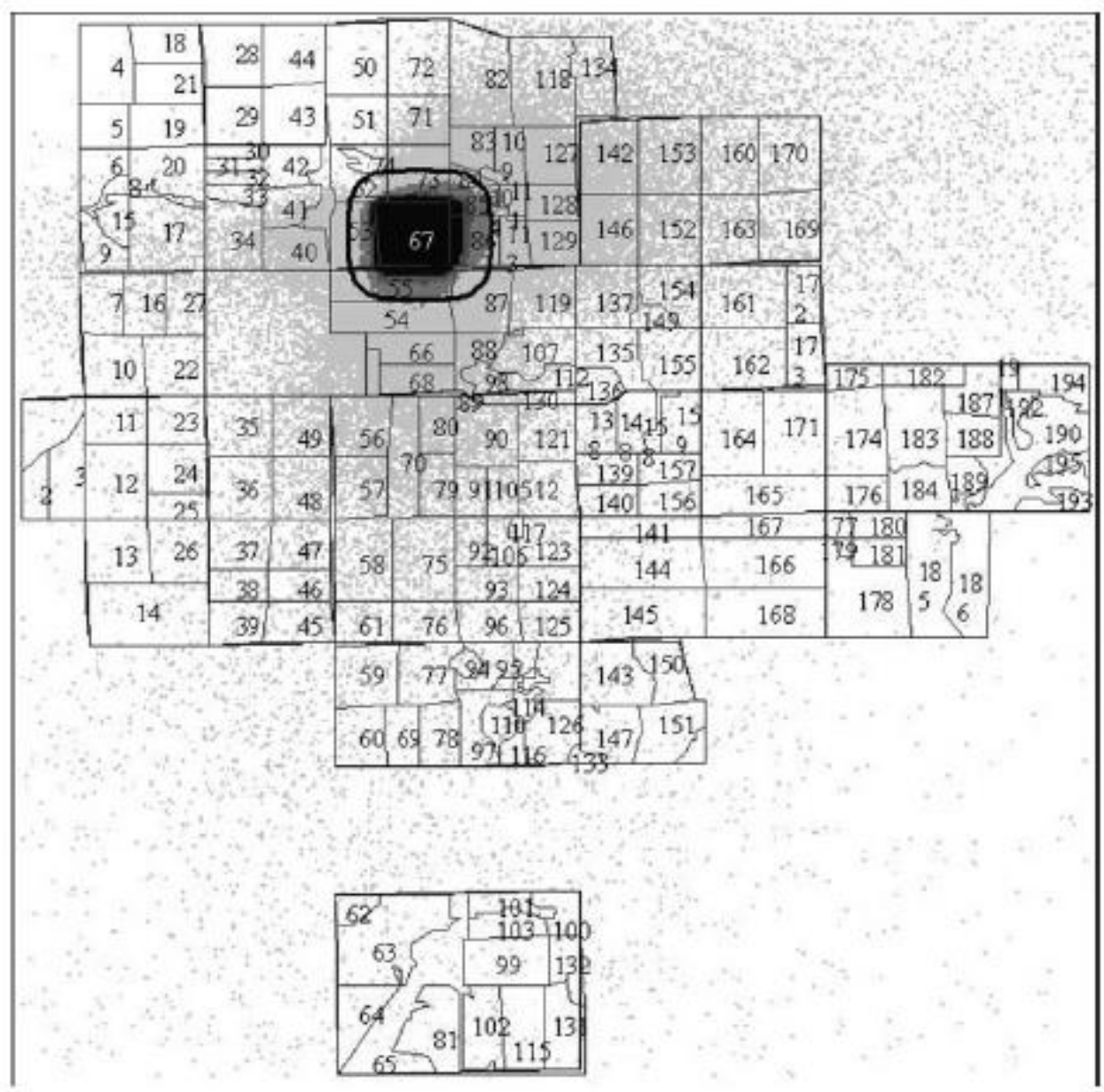


Wherrett et al. (2004) have recently quantified a relationship between ascospore-production and phoma stem canker severity in oilseed rape. With respect to a potential of 34_106 ascospores per stem (or 1.7_109 spores $\mathrm{m}$ )2, considering 50 affected stem fragments $\mathrm{m}$ )2), a disease index gradient (a calculation based on numbers of plants affected in each of 6 canker severity classes (Wherrett et al., 2004)] of 0-40, 40-50, 50-60 and $>60 \%$ was observed with roughly $1,3,6,8$ and $>8 \%$ spore-load (relative proportion of total spore production over 30 days after emergence), respectively. A similar relative scale was used to produce as outputs the concentration of ascospores dispersed in a grid (with squares $50 \_50 \mathrm{~m}$ ) in five concentrations - white (no spores), light grey ( $0-1 \%$ of spore-load), grey (1-3\% of spore-load), dark grey (3-8\% of spore-load) and black (>8\% of spore-load). Figure 2 also shows (black line around field 67) the significance of suggested separation distance $(500 \mathrm{~m})$ from the previous season's crop.

Figure 3. Comparison of the spatial dispersal of Leptosphaeria maculans ascospores obtained for four scenarios corresponding to six infected fields arranged in either a clustered or dispersed cropping pattern, with simplified or mixed tillage (three fields with simplified tillage and three fields with conventional tillage). The shading represents the proportion of ascospores dispersed from sources during 30 days after emergence, with a total production of $1.7 \times 10^{7}$ ascospores $/ \mathrm{m}^{2}(\square 0 \%, \square 0-1 \%, \square 1-3 \%, \square 3-8 \%$,

- $>8 \%$ ). The arrows point to locations in the region where crops could be grown without much risk expected of ascospore deposition.

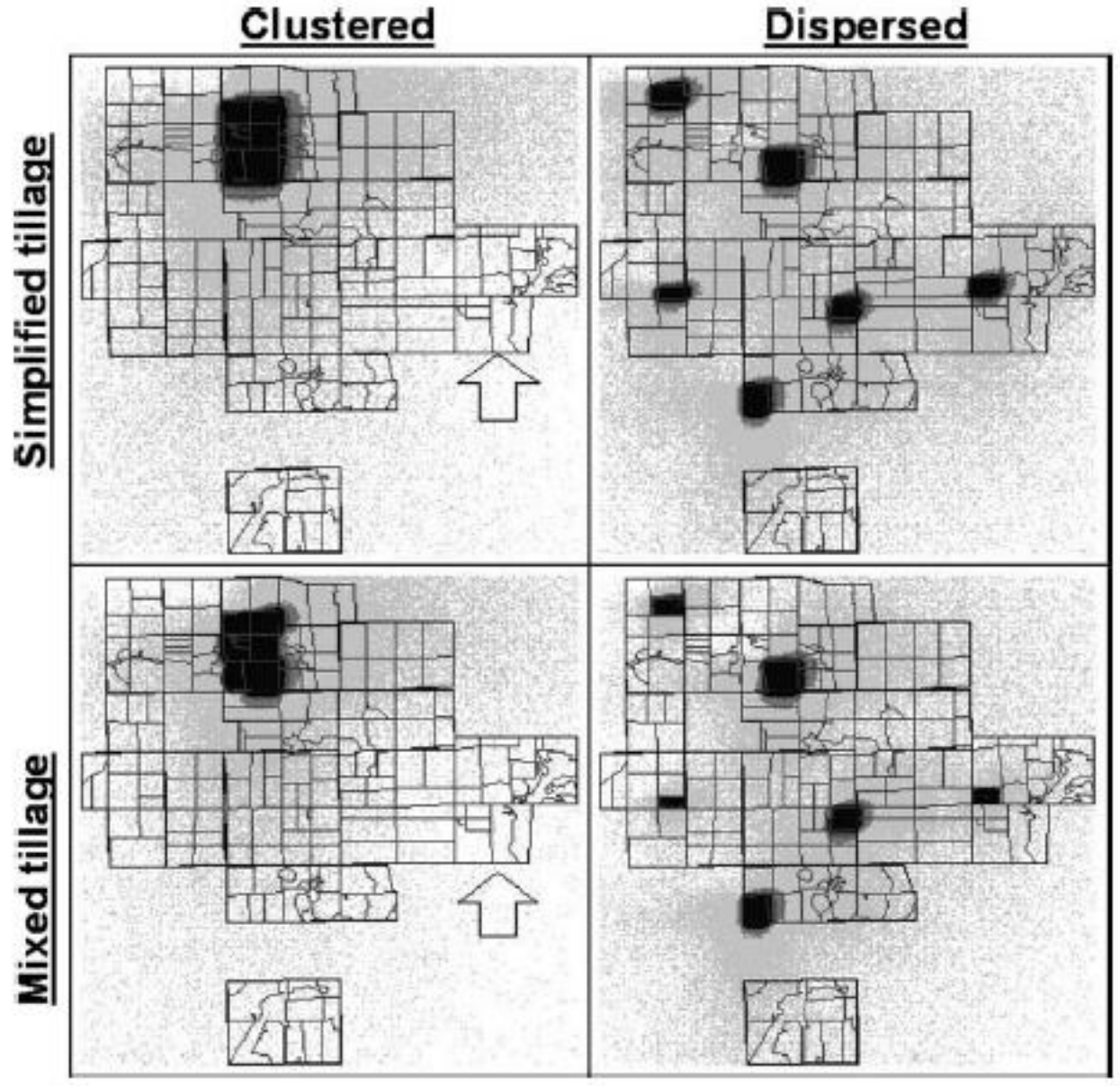

With the above assumptions, four scenarios were simulated, combining two cultural factors, cropping pattern (clustered fields and dispersed fields) and tillage (simplified or mixed) to show differences in spore dispersal in the region. For these scenarios, it was assumed that six oilseed the region. The infected fields were either clustered (fields 51, 52, 53, 67, 71 and 73, Figure 2) or scattered (21, 25, 60, 67, 123 and 176, Figure 2). Simplified tillage consisted of sowing directly after a cover-crop operation. Mixed tillage combined three fields with conventional tillage and three fields with simplified tillage. The conventional tillage consisted of ploughing after harvest and sowing after a rotary harrow operation. The spore load in the field with conventional tillage was 6\% of that observed with the simplified tillage (from Schneider, 2005). 
Figure 3 indicates that the concentration of ascospores is greatest, over the whole region, when the fields are in a clustered arrangement and have undergone simplified tillage. The simplified tillage practice with a scattered crop distribution, decreases the regional ascospore concentration by $13 \%$ (compared to the greatest), whereas mixed tillage, irrespective of cropping pattern, decreases the ascospore concentration by $45 \%$ (compared to the greatest). However, the spores are expected to be more widely distributed under the dispersed (spores landed in 59 and $44 \%$ of the area, respectively for simplified or mixed tillage) compared to clustered (spores landed in 37 and $28 \%$ of the area, respectively for simplified or mixed tillage) cropping patterns. It is evident from Figure 3 that in some locations in the region, crops could be grown without much risk expected of ascospore deposition (near arrow) under the clustered cropping pattern; this is not the case for the dispersed cropping pattern scenario.

\section{Discussion}

Oilseed rape is facing a dynamic situation where there are continual changes in the L. maculans population, with the host being exposed to potentially threatening 'metapopulations'. While strategies for enhancing durability of resistance have existed for some time, the potential for exploiting a more integrated management approach to increase durability has largely gone untapped, mainly due to inadequate knowledge on how to integrate available control strategies for enhancing durability of resistance. Strategies and options will vary in different regions of the world. A sound approach would be to apply an integrated approach to limit the selection pressure on the L. maculans population and limit the actual amount of inoculum produced by the L. maculans population (IAM concept). However, this type of management can be successfully achieved only by including the full array of available cultural practices to decrease residue/inoculum levels (e.g. by tillage, burning, crop rotation, application of chemicals to residues), avoid residue/inoculum (e.g. time of sowing, crop rotation), and judicious and timely application and/or delivery to the crop of fungicides and fertilisers. This requires spatially explicit modelling, especially as additional factors that influence L. maculans population evolution, such as mutation, genetic drift, migration, recombination and selection occurring within the pathogen populations, also need to be taken into consideration in relation to durability of the host resistance gene(s). Therefore, further work is required to transform the conceptual model presented in this paper into a completely validated simulation model to provide recommendations for strategies to be followed by farmers. The integrated disease management strategy required differs in relation to the resistance genes present in the crop. For example, the integrated management of cultivars with polygenic versus major gene resistance is likely to differ between different farms and regions. Previous models have generally focused only on one or at most a few of these aspects affecting durability of host resistance. In contrast, our model is the first that attempts to spatially accommodate the full range of the key aspects affecting durability of resistance, especially those associated with cultural control, with the aim of predicting the best options for maintaining and extending the durability of host resistance against L. maculans. Durability of host resistance can be achieved only by combining all these approaches rather than merely relying solely upon the development and deployment of resistant cultivars.

\section{Acknowledgements}

We are grateful for funding from the French Institut National de la Recherche Agronomique through the grant "Impact des innovations varietales", the Australian Grains Research and Development Corporation, The University of Western Australia, and the UK Biotechnology and Biological Sciences Research Council and Department for the Environment, Food and Rural Affairs.

\section{References}

Adugna, A 2004Alternate approaches in deploying genes for disease resistance in crop plantsAsian Journal of Plant Sciences3:618-623

Aubertot, JN, Pinochet, X, Doré, T 2004aThe effects of sowing date and nitrogen availability during vegetative stages on Leptosphaeria maculans development on winter oilseed rapeCrop Protection23:635-645 
Aubertot JN, Pinochet X, Reau R and Doré T (2004b) SimCanker: a simulation model for containing phoma stem canker of oilseed rape through cultural practices. Proceedings of the 4th International Crop Science Congress. 26 September-1 October. Brisbane, Australia. http://www. regional.org.au/au/cs/2004/

Barbetti MJ and Khangura RK (1999) Managing blackleg in the disease-prone environment of Western Australia. Proceedings of the 10th International Rapeseed Congress, September 26-29, Canberra, Australia. http://www. regional.org.au/au/gcirc/

Beatty, PH, Jensen, SE 2002Paenibacillus polymyxa produces fusaricidin-type antifungal antibiotics active against Leptosphaeria maculans, the causative agent of blackleg disease of canolaCanadian Journal of Microbiology48:159-169

Brun, H, Levivier, S, Somda, I, Ruer, D, Renard, M, Chèvre, AM 2000A field method for evaluating the potential durability of new resistance sources: Application to the Leptosphaeria maculans - Brassica napus pathosystemPhytopathology90;961-966

Brun, H, Ruer, D, Levivier, S, Somda, I, Chèvre, AM, Renard, M 2001Presence in Leptosphaeria maculans populations of isolates virulent on resistance introgressed into Brassica napus from B. nigra $\mathrm{B}$ genomePlant Pathology50:69-74

Caprio, MA 2001Source-sink between transgenic and non-transgenic habitats and their role in the evolution of resistanceJournal of Economic Entomology94:698-705

Cavan, G, Cussans, J, Moss, SR 2000Modelling different cultivation and herbicide strategies for their effect on herbicide resistance in Alopecurus myosuroides Weed Research40:561-568

Cerda, H, Wright, DJ 2004Modeling the spatial and temporal location of refugia to manage resistance in $B t$ transgenic cropsAgriculture, Ecosystems and Environment102:163-174

Chakraborty, BN, Chakraborty, U, Basu, K 1994Antagonism of Erwinia herbicola towards Leptosphaeria maculans causing blackleg disease of Brassica napus Letters in Applied Microbiology18:74-76

Chevillon, C, Raymond, M, Guillemaud, T, Lenormand, T, Pasteur, N 1999Population genetics of insecticide resistance in the mosquito Culex pipiens Biological Journal of the Linnean Society68:147-157

Crute, IR 1984The integrated use of genetic and chemical methods for control of lettuce downy mildew (BremiaLactucae Regel)Crop Protection3:223-241

Damgaard, C 1999Coevolution of a plant host-pathogen gene-for-gene system in a metapopulation model without cost of resistance or cost of virulenceJournal of Theoretical Biology20:11-12

Delourme, R, Chèvre, AM, Brun, H, Rouxel, T, Balesdent, M, Dias, JS, Salisbury, P, Renard, M, Rimmer, SR 2006Major gene and polygenic resistance to L. maculans in oilseed rape (Brassica napus)European Journal of Plant Pathology 114:41-52

Waard, MA 1993Management of resistance to pesticidesZadoks, JC eds. Modern Crop Protection: Development and PerspectivesWageningen PersWageningen, The Netherlands53-60

Diggle, AJ, Salam, MU, Thomas, GJ, Yang, HA, O’Connell, M, Sweetingham, MW 2002Anthracnose Tracer: A spatiotemporal model for simulating the spread of anthracnose in a lupin fieldPhytopathology92:11101121

Finckh, MR, Gacek, ES, Goyeau, H, Lannou, C, Merz, C, Mundt, CC, Munk, L, Nadziak, J, Newton, AC, Vallavieille-Pope, C, Wolfe, MS 2000Cereal variety and species mixtures in practice, with emphasis on disease resistanceAgronomie20;813-837

Fitt, BDL, Brun, H, Barbetti, MJ, Rimmer, SR 2006World-wide importance of phoma stem canker (Leptosphaeria maculans and L. biglobosa) on oilseed rape (Brassica napus)European Journal of Plant Pathology114:3-15

Gazzoni, DL 1998Modeling insect resistance to insecticides using Velvetbean Caterpillar (Anticarsia gemmatalis) as an examplePesticide Science53:109-122

Hammond, KE, Lewis, BG 1986The timing and sequence of events leading to stem canker disease in populations of Brassica napus var. oleifera in the fieldPlant Pathology35;551-564

Holt, J, Chancelor, TCB 1999Modelling the spatio-temporal deployment of resistant varieties to reduce the incidence of rice tungro disease in a dynamic cropping systemPlant Pathology48:453-461

Humpherson-Jones, FM, Burchill, RT 1982Chemical suppression of the sexual stage of Leptosphaeria maculans on oil-seed rape and turnip seed crop strawAnnals of Applied Biology100:281-288 
Hysek, J, Vach, M, Brozova, J, Sychrova, E, Civinova, M, Nedelnik, J, Hruby, J 2002The influence of the application of mineral fertilizers with the biopreparation supresivit (Trichoderma harzianum) on the health and the yield of different cropsArchives of Phytopathology and Plant Protection35:115-124

Kharbanda PD (1993) Blackleg of Canola in Alberta: Investigations on Biology, Epidemiology and Management. Alberta Environmental Centre, Vegreville, AB. AECV93-R5. 86 pp

Kharbanda PD, Yang J, Beatty P, Jensen S and Tewari JP (1999) Biocontrol of Leptosphaeria maculans and other pathogens of canola with Paenibacillus polymyxa PKB1. Proceedings of the 10th International Rapeseed Congress. Canberra, Australia. http://www.regional.org.au/au/gcirc/

Kiyosawa, S 1982Genetics and epidemiological modeling of breakdown of plant disease resistanceAnnual Review of Phytopathology20:93-117

Laxminarayan, R, Simpson, RD 2002Refuge strategies for managing pest resistance in transgenic agricultureEnvironmental and Resource Economics22:521-536

Leonard, KJ 1997Modelling gene frequency dynamicsCrute, IRHolub, EBBurdon, JJ eds. The Gene-for-Gene Relationship in Plant-Parasite InteractionsCAB InternationalLondon21:12-30

LePage, R, Penaud, A 1995Tout se joue avec le premier pic d'ascosporesCETIOM - Oléoscope28:23-27

Li, H, Barbetti, MJ, Sivasithamparam, K 2003aResponses of Brassica napus cultivars to Leptosphaeria maculans field isolates from Western AustraliaBrassica5:25-34

Li, H, Sivasithamparam, K, Barbetti, MJ 2003bBreakdown of a Brassica rapa ssp. sylvestris single dominant blackleg resistance gene in B. napus rapeseed by Leptosphaeria maculans field isolates in AustraliaPlant Disease87:752

Li, H, Damour, L, Sivasithamparam, K, Barbetti, MJ 2004Increased virulence and physiological specialization among Western Australian isolates of Leptosphaeria maculans breaking down existing single dominant gene-based resistance in six cultivars of Brassica napus Brassica6:9-16

Li, H, Barbetti, MJ, Sivasithamparam, K 2005Hazard from reliance on cruciferous hosts as sources of major gene based resistance for managing blackleg (Leptosphaeria maculans) diseaseField Crops Research91:185-191

Linacre, NA, Thompson, CJ 2004Dynamics of insect resistance in Bt-cornEcological Modelling 171:271-278

Lyngkjaer, MF, Newton, AC, Atzema, JL, Baker, SJ 2000The barley mlo-gene: An important powdery mildew resistance sourceAgronomie20:745-756

Maksymiak MS and Hall AM (2000) Biological control of Leptosphaeria maculans (anamorph Phoma lingam) causal agent of blackleg/canker on oil seed rape by Cyanthus striatus, a bird's nest fungus. The BCPC Conference: Pests and Diseases, Volume 1. Proceedings of an International Conference held at the Brighton Hilton Metropole Hotel, Brighton, UK, 13-16 November, pp. 507-510

Marcroft, SJ, Sprague, SJ, Pymer, SJ, Salisbury, PA, Howlett, BJ 2003Factors affecting production of inoculum of the blackleg fungus Leptosphaeria maculans in south-eastern AustraliaAustralian Journal of Experimental Agriculture43:1231-1236

Marcroft, SJ, Sprague, SJ, Pymer, SJ, Salisbury, PA, Howlett, BJ 2004Crop isolation, not extended rotation length, reduces blackleg (Leptosphaeria maculans) severity of canola (Brassica napus) in south-eastern AustraliaAustralian Journal of Experimental Agriculture44:601-606

McDonald, BA, Linde, C 2002The population genetics of plant pathogens and breeding strategies for durable resistanceEuphytica124;163-180

Mundt, CC 2002Use of multiline cultivars and cultivar mixtures for disease managementAnnual Review of Phytopathology40:381-410

Mundt, CC, Cowger, C, Garrett, K 2002Relevance of integrated management to disease durabilityEuphytica124:245-252

Neve, P, Diggle, AJ, Smith, FP, Powles, SB 2003Simulating evolution of glyphosate resistance in Lolium rigidum I: Population biology of a rare resistance traitWeed Research43:404-417

Onstad, DW, Guse, CA, Spencer, JL, Levine, E, Gray, ME 2001Modeling the dynamics of adaptation to transgenic corn by western corn rootworm (Coleoptera: Chrysomelidae)Journal of Economic Entomology94:529-540

Palumbo, JC, Horowitz, AR, Prabhaker, N 2001Insecticidal control and resistance management for Bemisia tabaci Crop Protection20:739-765 
Parlevliet, JE 2002Durability of resistance against fungal, bacterial and viral pathogens: present situationEuphytica124:147-156

Paul, VH, Rawlinson, CJ 1992Diseases and Pests of RapeVerlag Th. Mann Gelsenkirchen-BuerGermany

Peck, SL, Gould, F, Ellner, SP 1999Spread of resistance in spatially extended regions of transgenic cotton: Implications for management of Heliothis virescens (Lepidoptera: Noctuidae)Journal of Economic Entomology92:1-16

Penaud A, Bernard C, Maisonneuve C, Pérès A and Pilorgé E (1999) Decision rules for a chemical control of Leptosphaeria maculans. Proceedings of the 10th International Rapeseed Congress, September 26-29, Canberra, Australia. http://www.regional.org.au/au/gcirc/

Petrie, GA 1995Effects of chemicals on ascospore production by Leptosphaeria maculans on blackleg-infected canola stubble in SaskatchewanCanadian Plant Disease Survey75:45-50

Poisson B and Pérès A (1999) Study of rapeseed susceptibility to primary contamination of Leptosphaeria maculans in relation to plant vegetative stage. Proceedings of the 10th International Rapeseed Congress, September 26-29, Canberra, Australia. http://www.regional.org.au/au/gcirc/

Rawlinson, CJ, Muthyalu, G, Cayley, GR 1984Fungicide effects on light leaf-spot, canker, crop growth and yield of winter oil-seed rapeJournal of Agricultural Science103:613-628

Rouxel, T, Penaud, A, Pinochet, X, Brun, H, Gout, L, Delourme, R, Schmit, J, Balesdent, MH 2003A ten-year survey of populations of Leptosphaeria maculans in France indicates a rapid adaptation towards the Rlm1 resistance gene of oilseed rapeEuropean Journal of Plant Pathology 109:871-881

Salam MU, Galloway J, Khangura RK, Diggle AJ, MacLeod WJ and Barbetti MJ (2001) Spatial spread of Blackleg in canola - A regional scale simulation model. Conference Proceedings, 12th Australian Research Assembly on Brassicas, Geelong, Victoria, Australia, pp. 101-105

Salam, MU, Khangura, RK, Diggle, AJ, Barbetti, MJ 2003Blackleg Sporacle: A model for predicting onset of pseudothecia maturity and seasonal ascospore showers in relation to blackleg of canolaPhytopathology93:1073-1081

Schneider O (2005) Analyse des effets du mode de gestion des résidus de colza sur l'initiation du cycle de Leptosphaeria maculans (Desm.) Ces et de Not. PhD thesis Institut National Agronomique Paris-Grignon, $93 \mathrm{pp}$

Schwarzbach, E 1998The mlo-based resistance of barley to mildew and the response of mildew populations to the use of varieties with the mlo geneCzech Journal of Genetics and Plant Breeding34:3-10

Shi-Mai, Z 1991PANCRIN, a prototype model of the pandemic cultivar-race interaction of yellow rust on wheat in ChinaPlant Pathology40:287-295

Söchting, HP, Verreet, JA 2004Effects of different cultivation systems (soil management, nitrogen fertilization) on the epidemics of fungal diseases in oilseed rape (Brassica napus L. var. napus)Zeitschrift Fur Pflanzenkrankheiten Und Pflanzenschutz-Journal of Plant Diseases and Protection11:11-29

Sprague, SJ, Balesdent, MH, Brun, H, Hayden, HL, Marcroft, SJ, Pinochet, X, Rouxel, T, Howlett, BJ 2006Major gene resistance in Brassica napus (oilseed rape) is overcome by changes in virulence of populations of Leptosphaeria maculans in France and AustraliaEuropean Journal of Plant Pathology114:33-40

Storer, NP, Peck, SL, Gould, F, Duyn, JW, Kennedy, GG 2003Sensitivity analysis of a spatially-explicit stochastic simulation model of the evolution of resistance in Helicoverpa zea (Lepidoptera: Noctuidae) to $B t$ trangenic corn and cottonJournal of Economic Entomology96:173-187

Sun, P, Fitt, BDL, Steed, JM, Underwood, CT, West, JS 2001Factors affecting development of phoma canker (Leptosphaeria maculans) on stems of winter oilseed rape (Brassica napus) in southern EnglandAnnals of Applied Biology139:227-242

Thürwächter, F, Garbe, V, Hoppe, HH 1999Ascospore discharge, leaf infestation and variations in pathogenicity as criteria to predict impact of Leptosphaeria maculans on oilseed rapeJournal of Phytopathology 147:215222

Turkington, TK, Clayton, GW, Klein-Gebbinck, H, Woods, DL 2000Residue decomposition and blackleg of canola: Influence of tillage practicesCanadian Journal of Plant Pathology22:150-154 
Vacher, C, Bourguet, D, Rousset, F, Chevillon, C, Hochberg, ME 2003Modelling the spatial configuration of refuges for a sustainable control of pests: A case study of Bt cottonJournal of Evolutionary Biology16:378387

Bosch, F, Gilligan, CA 2003Measures of durability of resistancePhytopathology93:616-625

West, JS, Kharbanda, PD, Barbetti, MJ, Fitt, BDL 2001Epidemiology and management of Leptosphaeria maculans (phoma stem canker) on oilseed rape in Australia, Canada and EuropePlant Pathology50:10-27

West, JS, Fitt, BDL, Leech, PK, Biddulph, JE, Huang, Y-J, Balesdent, MH 2002Effects of timing of Leptosphaeria maculans ascospore release and fungicide regime on phoma leaf spot and phoma stem canker development on winter oilseed rape (Brassica napus) in southern EnglandPlant Pathology51:454463

Wherrett, AD, Sivasithamparam, K, Barbetti, MJ 2003Chemical manipulation of Leptosphaeria maculans (blackleg disease) pseudothecial development and timing of ascospore discharge from canola (Brassica napus) residuesAustralian Journal of Agricultural Research54:837-848

Wherrett, AD, Sivasithamparam, K, Barbetti, MJ 2004Establishing the relationship of ascospore loads with blackleg (Leptosphaeria maculans) severity on canola (Brassica napus)Australian Journal of Agricultural Research55:849-854

Wolfe, MS 1984Trying to understand and control powdery mildewPlant Pathology33:451-466

Zhou, Y, Fitt, BDL, Welham, SJ, Gladders, P, Sansford, CE, West, JS 1999Effects of severity and timing of stem canker (Leptosphaeria maculans) symptoms on yield of winter oilseed rape (Brassica napus) in the UKEuropean Journal of Plant Pathology105:715-728 